\title{
Factors Associated with Practice of Covid-19 Precautionary Measures among Clients Visiting A Teritiary Hospital, Addis Ababa, Ethiopia
}

Hailemichael Bizuneh ( $\boldsymbol{\nabla}$ hailmichaelbiz@gmail.com )

SPHMMC: St Paul's Hospital Millennium Medical College https://orcid.org/0000-0003-0586-7562

Shikur Mohammed

St Paul's Hospital Millennium Medical College

Aman Yesuf

St Paul's Hospital Millennium Medical College

\section{Research}

Keywords: COVID-19, SARS-CoV-2, Attitude, Practice, Hospital, Ethiopia

Posted Date: July 13th, 2021

DOI: https://doi.org/10.21203/rs.3.rs-666252/v1

License: (영 This work is licensed under a Creative Commons Attribution 4.0 International License. Read Full License 


\section{Abstract}

Background: Despite efforts to contain the COVID-19 virus, Addis Ababa, the country's COVID-19 epicenter, is experiencing a sharp increase in the number of cases and death rate. While poor public adherence to individual COVID-19 precautionary measures is evident, factors associated with it are not well studied. We aimed to assess the level of practice of COVID-19 precautionary measures and associated factors.

Methods: This was a hospital-based cross-sectional study conducted from February $1^{\text {st }}$ to $15^{\text {th }}, 2021$ at Saint Paul's Hospital Millennium Medical College, a tertiary hospital in Addis Ababa. We used a structured questionnaire to conduct a face-to-face exit interview with randomly selected clients visiting the hospital. Binary and multivariable logistic regressions were implemented to examine factors associated with prevention practice.

Results: We analyzed data from 262 participants. The mean age of participants was $36(S D=12)$ years. The majority $(207,79 \%)$ of the study participants had a favorable attitude towards prevention and control measures of the disease. A little above half $(116,55.7 \%)$ of the respondents had a satisfactory level of practice of COVID-19 precautionary measures. Being a resident of the capital city [AOR: 2.25 (1.22-4.15)], and having a favorable attitude [AOR: (AOR: 4.88(2.08-11.68)] were significantly associated with satisfactory COVID-19 precautionary practice.

Conclusions: The level of COVID-19 precautionary practice was unsatisfactory. A favorable attitude and stricter enforcement of COVID-19 preventive measures were associated with adherence to precautionary practices. The findings highlight the need for a public health education strategy targeted at improving attitudes of the community on COVID-19 preventive practice.

\section{Background}

Since its emergence in December 2019, the coronavirus disease (COVID-19) caused by severe acute respiratory syndrome coronavirus 2 (SARS-CoV-2) has progressed into a pandemic $(1,2)$. Globally, as of May 11, 2021, there have been over 158 million confirmed cases including over 3 million deaths in Africa (3). The second-most populous African country, Ethiopia, and has reported over 260,000 confirmed cases and 3,888 deaths $(4,5)$. In Addis Ababa, the capital city, a sharp rise in high positivity rate, health facility admissions, and deaths were reported indicating a high community transmission (4). In the past year, the Ethiopian Ministry of Health $(\mathrm{MoH})$ has implemented comprehensive COVID-19 prevention measures. Notably, the ministry enacted a directive that aimed to enforce COVID-19 Public Health and Social Measures (PHSM). Despite this effort, poor public adherence to precautionary measures seems to be a key factor in impeding efforts to slow the spread of COVID-19 (6). With only one percent of the country's population vaccinated as of May 11, 2021, and a growing concern of new COVID-19 variants, proper practice of precautionary measures remains the first line of defense (7).

According to the World Health Organization (WHO), engaging in the proper practice of precautionary behaviors including personal hygiene, wearing a face mask, and maintaining social distance, significantly contribute to controlling the spread of $\operatorname{COVID-19}(6,8)$. A multitude of factors affects the level of individual 
prevention practice in a population. Among others, individual awareness, knowledge, attitude, and perception of risk are key in the adoption of precautionary practices $(6,8,9)$. However, there is scarce evidence as to which of these factors contribute to a practical adoption and adherence to precautionary practices. The few studies conducted previously were limited to subsets of the population, particularly health care workers (10-12). Our study aimed to investigate the level and factors associated with COVID-19 prevention practice among clients visiting a tertiary hospital in Addis Ababa.

\section{Methods}

\section{Study design and setting}

This hospital-based cross-sectional study was conducted from February 1st to 15th 2021 at Saint Paul's Hospital Millennium Medical College (SPHMMC), in Addis Ababa. This tertiary hospital is the second-largest referral and teaching hospital in the country. Currently, it has an inpatient capacity of 700 beds and an average of 1,200 emergency and outpatient clients daily. The hospital is one of the few COVID-19 centers in the capital city and currently runs the largest COVID-19 treatment center in the country.

\section{Study population and sampling}

All clients visiting the hospital were the source population, of which randomly selected clients were included as a study population. Being an adult (> 18 years) was an inclusion criterion and history of COVID-19 infection was an exclusion criterion. A single population proportion formula with a marginal error of $5 \%(\mathrm{~d}=$ 0.05); and a standard score corresponding to $95 \%$ confidence was considered to determine the sample size. We calculated separate sample sizes for each of the two study objectives (level of practice and factors associated with practice). We took the prevalence ( $p$ ) of the practice of 'hand washing' from a similar study $(77.3 \%)(13)$ which yielded the maximum sample size of 270 . After considering a $5 \%$ non-response rate, the final sample size for this study was 284 clients.

A systematic random sampling technique was used to identify respondents and conduct a face-to-face exit interview. The number of patients who visited the hospital's outpatient department on a daily basis three months before data collection was determined by consulting client register books. A sampling interval was determined by dividing the expected number of clients by the total sample size, which was then proportionally allocated to major departments in the hospital.

\section{Study variables and measurement}

COVID-19 precautionary measure was the dependent variable in this study, and the independent variables were divided into socio-demographic characteristics: age, gender, education, family size, marital status, and occupation; knowledge level and source of information on COVID-19 transmission, prevention, and control methods; attitude towards COVID-19 prevention, and control measures; perceived level of risk of contracting COVID-19 and presence of underlying chronic illnesses of the respondent or their family.

Bloom's cut-off point of $>80 \%$ on the aggregate score was adapted to rank respondents' overall knowledge, attitude, and practice scores (14). Practice, knowledge, and attitude were operationally defined as follows: 
Satisfactory practice: a score of $>=80 \%$ on nine items with a possible response and point score of "Always $=2$ ", "Occasionally $=1$ " and "Never $=0$ " assessing the practice of COVID-19 precautionary measures. Adequate Knowledge: a score of $>=80 \%$ on 19 items with a possible response and point score of "Yes $=1$ " or "No $=0$ " assessing the knowledge of COVID-19 prevention measures, transmission ways, and disease symptoms. Favorable attitude: a score of $>=80 \%$ on five, five point-Likert scale items with a response and point score of "Strongly agree = 5", "Agree = 4", "Neutral = 3", "Disagree = 1" to "Strongly disagree = 0" assessing the attitude towards COVID-19 prevention and control measures.

\section{Data collection}

Data were collected by trained data collectors using a structured tool adapted from WHO's COVID-19 knowledge, risk perceptions, precautionary behaviors survey tool (15). The tool was pre-tested on a sample of clients at a nearby Selam health center. The questionnaire was translated into Amharic (the local working language) and back to English to assess the consistency of meaning of items on the two tools. The Amharic version of the questionnaire was used for the interview.

\section{Data analysis}

The collected data were entered into Epi Info and exported to SPSS version 23 for analysis. Firstly, descriptive statistics such as frequency, proportion, mean and standard deviation were computed. Then, binary logistic regression analysis was implemented to examine factors associated with prevention practice. Variables with a p-value of 0.25 or lower on binary analysis were further analyzed in a multivariable logistic regression model. Odds ratio with $95 \%$ Confidence Interval $(\mathrm{Cl})$ was used to test significance association.

\section{Ethical consideration}

Ethical clearance was obtained from SPHMMC Institutional Review Board. The participants were informed on the purpose of the study, confidentiality, voluntary participation, anonymity, and withdrawal. Oral informed consent was obtained from all the respondents.

\section{Results}

\section{Socio-demographic characteristics}

A total of 284 clients were initially approached for an interview. After excluding those who refused to participate and those with incomplete responses, $262(92.2 \%)$ respondents were included in the final analysis. The mean age of participants was $36( \pm 12)$ years. [Table 1] 
Table 1

Socio-demographic characteristics of respondents

\begin{tabular}{|c|c|c|}
\hline Characteristics & Frequency & Percentage \\
\hline \multicolumn{3}{|l|}{ Age } \\
\hline $18-29$ & 86 & 32.8 \\
\hline $30-49$ & 131 & 50 \\
\hline $50-70$ & 45 & 17.2 \\
\hline \multicolumn{3}{|l|}{ Sex } \\
\hline Male & 140 & 53.4 \\
\hline Female & 122 & 46.6 \\
\hline \multicolumn{3}{|l|}{ Religion } \\
\hline Orthodox & 141 & 53.9 \\
\hline Muslim & 60 & 22.9 \\
\hline Protestant and Jehovah's witness & 61 & 23.2 \\
\hline \multicolumn{3}{|l|}{ Marital Status } \\
\hline Single & 91 & 34.7 \\
\hline Married & 156 & 59.5 \\
\hline Divorced, Widowed or Separated & 15 & 5.8 \\
\hline \multicolumn{3}{|l|}{ Educational status } \\
\hline Unable to read and write & 17 & 6.5 \\
\hline Able to read and write & 12 & 4.6 \\
\hline Primary (1-8th grade) & 35 & 13.4 \\
\hline Secondary (9-12th grade) & 90 & 34.3 \\
\hline College and above & 108 & 41.2 \\
\hline \multicolumn{3}{|l|}{ Occupational status } \\
\hline Employed & 252 & 96.2 \\
\hline Unemployed & 10 & 3.8 \\
\hline \multicolumn{3}{|l|}{ Place of residence } \\
\hline Addis Ababa (capital city) & 146 & 55.7 \\
\hline Out of Addis Ababa & 116 & 44.3 \\
\hline
\end{tabular}




\section{Perceived risk of COVID-19}

Just above a third $(101,38.5 \%)$ of the respondents reported that they had a chronic illness; diabetes was the most commonly reported $(35,34.6 \%)$. The majority $(79.8,50.8 \%)$ of the respondents perceived their level of risk of contracting COVID-19 was "low" or "medium". [Table 2]

Table 2

Perceived risk of COVID-19 among respondents

\begin{tabular}{|lll|}
\hline Characteristics & Frequency & Percentage \\
\hline Do you have a chronic illness? ( $\mathbf{n = 2 6 2 )}$ & & \\
\hline Yes & 101 & 38.5 \\
\hline No & 155 & 59.2 \\
\hline I do not know & 6 & 2.3 \\
\hline What is your chronic illness? ( $\mathbf{n}=\mathbf{1 0 1})$ & & \\
\hline Heart disease & 11 & 10.9 \\
\hline Hypertension & 30 & 29.7 \\
\hline Diabetes & 35 & 34.6 \\
\hline Other* & 25 & 24.8 \\
\hline High-risk family member (elderly, with chronic illness) (n=262) & & 30.9 \\
\hline Yes & 81 & 69.1 \\
\hline No & 181 & \\
\hline Perceived level of risk for contracting CoVID 19 (n=262) & & 27.9 \\
\hline High & 73 & 50.8 \\
\hline Medium & 133 & 19.8 \\
\hline Low & 52 & 1.5 \\
\hline I do not know & 4 & \\
\hline *asthma, epilepsy, kidney disease and cancer & & \\
\hline
\end{tabular}

\section{Knowledge of COVID-19 transmission and prevention}

Close to a third of the respondents $(82,31.3 \%)$ reported that eating homemade spices such as ginger was protective of COVID-19. The overall knowledge score showed that just over half $(139,53.0 \%)$ of the respondents had adequate knowledge of COVID-19 mode of transmission, symptoms, and prevention methods. [Table 3] 
Table 3

Knowledge of COVID-19 prevention, symptoms, and transmission among respondents

\begin{tabular}{|l|}
\hline Characteristics \\
\hline Primary source of information about COVID-19
\end{tabular}

TV/radio

246

93.9

Health professional

141

53.8

Social media

122

46.6

Family/friends

77

29.4

Other (newspapers and religion institutions)

6

2.3

\section{Ways of COVID-19 transmission}

Respiratory droplets of infected person

206

78.6

Direct contact with infected person

250

95.4

Indirect contact through infected surface

12

4.6

\section{Main symptoms of COVID-19}

Fever

213

81.3

Fatigue

115

43.9

Dry cough

230

87.8

Sore throat

126

48.1

Headache

29

11

Other*

39

14.8

\section{Modes of prevention of COVID-19}

Avoid crowded places

97

Keep physical distance to a minimum of 2 meters

148

56.5

Wear a mask

242

92.4

Avoided shaking hands

190

72.5

Wash hands with water \& soap for at least 20 seconds

191

72.9

Clean hands with alcohol-rubbing or sanitizer

165

63

Cover mouth/nose with elbow when coughing/sneezing

65

24.8

*chills, shortness of breath, joint pain, and sneezing

**drink hot beverages, wear gloves, consume a balanced diet, and get vaccinated 


\begin{tabular}{|lll|}
\hline Characteristics & Frequency & Percentage \\
\hline Not touch eyes, nose, or mouth with unwashed hands & 65 & 24.8 \\
\hline Clean repeatedly touched surfaces & 26 & 9.9 \\
\hline Other* & 8 & 3.05 \\
\hline Eating homemade spices such as ginger is protective of COVID-19 & 82 & 31.3 \\
\hline Infected persons cannot transmit the disease if they have no cough & 26 & 9.9 \\
\hline There is no need for a suspected person to be quarantined & 9 & 3.4 \\
\hline Level of knowledge & & \\
\hline Adequate knowledge & 139 & 53 \\
\hline Inadequate knowledge & 123 & 47 \\
\hline *chills, shortness of breath, joint pain, and sneezing & & \\
\hline **drink hot beverages, wear gloves, consume a balanced diet, and get vaccinated & \\
\hline Attitude towards COVID-19 prevention and Control measures
\end{tabular}

Most $(115,43.9 \%)$ of the respondents felt that they had a role in reducing the spread of COVID-19. Overall, the majority $(207,79 \%)$ of the study participants had a favorable attitude towards control and prevention measures of the disease. [Table 4] 
Attitude of respondents towards COVID-19 prevention and control measures

Characteristic

If I were infected with COVID-19, I would self-isolate

Strongly agree

Agree

Neutral

Disagree

Strongly disagree

I am willing to do a voluntary test for COVID 19

Strongly agree

Agree

Neutral

Disagree

Strongly disagree

As an individual, I have a role in reducing the spread of the COVID-19

Strongly agree

126

104

20

12

0

20

26

11

8

Agree

Neutral

Disagree

Strongly disagree

If I were infected with COVID-19, I would disclose my status to relatives, friends, or colleagues

Strongly agree

Agree

Neutral

Disagree

Strongly disagree

Whether young or old, everyone should equally implement COVID-19 prevention practice

Strongly agree
115

43.9

90

119

0

1

0.4

Frequency

Percentage

51.1

45.4

3.1

0

34.4

7.6

9.9

4.2

48.1

39.7

7.6

4.6

0 


\begin{tabular}{|lll|}
\hline Characteristic & Frequency & Percentage \\
\hline Agree & 86 & 32.8 \\
\hline Neutral & 5 & 1.9 \\
\hline Disagree & 9 & 3.4 \\
\hline Strongly disagree & 0 & 0 \\
\hline Level of attitude & & \\
\hline Favorable & 207 & 79 \\
\hline Unfavorable & 55 & 21 \\
\hline COVIID-19 Precautionary Practice
\end{tabular}

\section{COVID-19 precautionary practice}

Most $(190,72.5 \%)$ of the respondents reported that they always wore face masks when going outside of their house. The overall practice score showed that just above half $(116,55.7 \%)$ of the respondents had a satisfactory practice of COVID-19 precautionary measures. [Table 5] 
Table 5

COVID-19 prevention practice among respondents in the preceding two weeks

\begin{tabular}{|c|c|c|}
\hline Characteristics & Frequency & Percentage \\
\hline \multicolumn{3}{|c|}{ Avoided going to crowded places or social gatherings } \\
\hline Always & 64 & 24.4 \\
\hline Occasionally & 151 & 57.6 \\
\hline Never & 47 & 17.9 \\
\hline \multicolumn{3}{|c|}{ Wore facemask when leaving home } \\
\hline Always & 190 & 72.5 \\
\hline Occasionally & 70 & 26.7 \\
\hline Never & 2 & 0.8 \\
\hline \multicolumn{3}{|c|}{ Avoided shaking hands with other people } \\
\hline Always & 119 & 45.4 \\
\hline Occasionally & 117 & 44.7 \\
\hline Never & 26 & 9.9 \\
\hline \multicolumn{3}{|c|}{ Washed hands with water and soap for at least 20 seconds } \\
\hline Always & 113 & 43.1 \\
\hline Occasionally & 121 & 46.2 \\
\hline Never & 28 & 10.7 \\
\hline \multicolumn{3}{|c|}{ Kept physical distance to a minimum of 2 meters } \\
\hline Always & 30 & 11.5 \\
\hline Occasionally & 134 & 51.1 \\
\hline Never & 98 & 37.4 \\
\hline \multicolumn{3}{|c|}{ Avoided touching eyes, nose or mouth before washing hands } \\
\hline Always & 74 & 28.3 \\
\hline Occasionally & 147 & 56.1 \\
\hline Never & 41 & 15.6 \\
\hline \multicolumn{3}{|c|}{ Covered mouth and nose when coughing or sneezing } \\
\hline Always & 118 & 45 \\
\hline Occasionally & 113 & 43.1 \\
\hline
\end{tabular}




\begin{tabular}{|lll|}
\hline Characteristics & Frequency & Percentage \\
\hline Never & 31 & 11.8 \\
\hline Cleaned hands with alcohol-based sanitizer & & \\
\hline Always & 93 & 35.5 \\
\hline Occasionally & 132 & 50.4 \\
\hline Never & 37 & 14.1 \\
\hline Disinfected mobile phone or personal articles with sanitizer & & \\
\hline Always & 68 & 26 \\
\hline Occasionally & 99 & 37.8 \\
\hline Never & 95 & 36.2 \\
\hline CoVID-19 practice level & & \\
\hline Satisfactory & 116 & 55.7 \\
\hline Unsatisfactory & 146 & 44.3 \\
\hline
\end{tabular}

\section{Factors associated with COVID-19 prevention practice}

The binary analysis outputs showed that respondents who had primary school education had greater odds of poor practice as compared to those with no formal education (Crude odds ratio (COR) 0.32 (0.14-0.76)). And those who had a better knowledge of COVID-19 had greater odds of practice of satisfactory precautionary measures (COR 1.93 (1.17-3.17). However, after multivariable analysis, only the place of residence of Addis Ababa (Adjusted odds ratio (AOR): 2.25 (1.22-4.15)) and favorable attitude towards COVID-19 prevention and control measures (AOR: 4.88 (2.08-11.68)) were significantly associated with practice. [Table 6] 
Table 6

Factors associated with COVID-19 prevention practice in regression analysis

\begin{tabular}{|c|c|c|c|c|c|}
\hline \multirow[t]{2}{*}{ Characteristics } & \multicolumn{2}{|l|}{ Practice } & \multirow{2}{*}{$\begin{array}{l}\text { COR }(95 \% \\
\mathrm{Cl})\end{array}$} & \multirow{2}{*}{$\begin{array}{l}\text { AOR }(95 \% \\
\text { Cl) }\end{array}$} & \multirow{2}{*}{$\begin{array}{l}\mathrm{P}- \\
\text { value }\end{array}$} \\
\hline & Satisfactory & Unsatisfactory & & & \\
\hline \multicolumn{6}{|l|}{ Marital status } \\
\hline Single & $33(36.3)$ & $58(63.7)$ & $\begin{array}{l}1.14 \\
(0.36- \\
3.61)\end{array}$ & $\begin{array}{l}2.85(0.51- \\
15.92)\end{array}$ & 0.233 \\
\hline Married & $78(50.0)$ & $78(50.0)$ & $\begin{array}{l}2(0.65- \\
6.12)\end{array}$ & $\begin{array}{l}3.27(0.62- \\
17.20)\end{array}$ & 0.163 \\
\hline Divorced/separated/windowed & $5(33.3)$ & 10(66.7) & 1 & 1 & \\
\hline \multicolumn{6}{|l|}{ Educational Status } \\
\hline No formal education & $18(62.1)$ & 11(37.9) & 1 & 1 & \\
\hline Primary & $15(42.9)$ & $20(57.1)$ & $\begin{array}{l}0.46(0.17- \\
1.25)\end{array}$ & $\begin{array}{l}0.33(0.09- \\
1.22)\end{array}$ & 0.097 \\
\hline Secondary & $31(34.4)$ & $59(65.6)$ & $\begin{array}{l}0.32(0.14- \\
0.76)\end{array}$ & $\begin{array}{l}0.40(0.12- \\
1.29)\end{array}$ & 0.125 \\
\hline College and above & $52(48.1)$ & $56(51.9)$ & $\begin{array}{l}0.57(0.25- \\
1.31)\end{array}$ & $\begin{array}{l}0.40(0.13- \\
1.29)\end{array}$ & 0.126 \\
\hline \multicolumn{6}{|l|}{ Place of residence } \\
\hline Addis Ababa & $81(55.5)$ & $65(44.5)$ & $\begin{array}{l}2.88(1.73- \\
4.82)\end{array}$ & $\begin{array}{l}2.25(1.22- \\
4.15)^{\star}\end{array}$ & 0.009 \\
\hline Out of Addis Ababa & $35(30.2)$ & $81(69.8)$ & 1 & & \\
\hline \multicolumn{6}{|l|}{$\begin{array}{l}\text { High risk family member } \\
\text { (elderly, with chronic illness) }\end{array}$} \\
\hline Yes & $23(28.4)$ & $58(71.6)$ & $\begin{array}{l}0.38(0.21- \\
0.66)\end{array}$ & $\begin{array}{l}0.88(0.44- \\
1.79)\end{array}$ & 0.73 \\
\hline No & $93(51.4)$ & $88(48.6)$ & 1 & 1 & \\
\hline \multicolumn{6}{|l|}{$\begin{array}{l}\text { Self-rate of level of risk of } \\
\text { contracting COVID } 19\end{array}$} \\
\hline High & $32(43.8)$ & $41(56.2)$ & $\begin{array}{l}2.34(0.23- \\
23.59)\end{array}$ & $\begin{array}{l}4.1(0.36- \\
48.77)\end{array}$ & 0.254 \\
\hline Medium & $51(38.3)$ & $82(61.7)$ & $\begin{array}{l}1.87(0.19- \\
18.43)\end{array}$ & $\begin{array}{l}5.26(0.46- \\
60.74)\end{array}$ & 184 \\
\hline Low & $32(61.5)$ & $20(38.5)$ & $\begin{array}{l}4.8(0.47- \\
49.39)\end{array}$ & $\begin{array}{l}9.49(0.79- \\
114.72)\end{array}$ & 0.077 \\
\hline I don't know & $1(25)$ & $3(75.0)$ & 1 & 1 & \\
\hline
\end{tabular}




\begin{tabular}{|c|c|c|c|c|c|}
\hline \multirow[t]{2}{*}{ Characteristics } & \multicolumn{2}{|l|}{ Practice } & \multirow{2}{*}{$\begin{array}{l}\text { COR }(95 \% \\
\mathrm{Cl})\end{array}$} & \multirow{2}{*}{$\begin{array}{l}\text { AOR }(95 \% \\
\text { Cl) }\end{array}$} & \multirow{2}{*}{$\begin{array}{l}\mathrm{P}- \\
\text { value }\end{array}$} \\
\hline & Satisfactory & Unsatisfactory & & & \\
\hline \multicolumn{6}{|c|}{$\begin{array}{l}\text { Knowledge of COVID-19 mode } \\
\text { of transmission, symptoms } \\
\text { and prevention }\end{array}$} \\
\hline Satisfactory & 72(51.8) & $67(48.2)$ & $\begin{array}{l}1.93(1.17- \\
3.17)\end{array}$ & $\begin{array}{l}1.14(0.6- \\
2.16)\end{array}$ & 0.697 \\
\hline Unsatisfactory & $44(35.8)$ & $79(64.2)$ & 1 & 1 & \\
\hline \multicolumn{6}{|c|}{$\begin{array}{l}\text { Attitude towards COVID-19 } \\
\text { prevention and control }\end{array}$} \\
\hline Favorable & $108(52.8)$ & $99(47.8)$ & $\begin{array}{l}6.4(2.88- \\
14.23)\end{array}$ & $\begin{array}{l}4.88(2.08- \\
11.68)^{\star}\end{array}$ & $<.0001$ \\
\hline Unfavorable & $8(14.5)$ & $47(85.5)$ & 1 & & \\
\hline
\end{tabular}

\section{Discussion}

Just above half (55.7\%) of the study participants had satisfactory COVID-19 prevention practices. The face mask was the most commonly utilized precautionary method. More than two-thirds of the respondents reported they always wore a face mask. This was in line with the knowledge assessment result where almost all of the respondents mentioned face masks as the primary means of prevention. This was also in agreement with previous studies that reported a positive association between COVID-19 knowledge and utilization of face masks (16). However, according to WHO, the use of a mask alone is insufficient to provide an adequate level of protection and must be combined with hand hygiene to prevent transmission of COVID-19 (17). In the present study, hand hygiene practice was low, as less than half of respondents reported washing hands with water and soap, and only a third reported using sanitizers. On top of this, hand hygiene practice levels are declining as compared to a year ago at the start of the pandemic $(13,18)$. This finding might indicate that inadequate hand hygiene might be hindering the effort to slow the spread of the virus.

In this study, the lowest score on COVID-19 precautionary measures was for social distancing; only a quarter of the respondents avoided crowded places or social gatherings, and a mere one-tenth maintained physical distance. This finding also markedly showed a decline as compared to previous studies (19). A multitude of factors can explain the poor adherence. For one, the odds of not adhering to all social distancing rules increases if a participant does not self-identify as highly vulnerable to $\operatorname{COVID-19}(18,19)$. Congruently, in this study, less than a third of the respondents perceived their risk of infection as high, indicating a lower perceived vulnerability. Another possible explanation could be that maintaining social distance may not be always entirely possible due to living in crowded areas (19) and use of public transportation, leading to unintentional non-adherence of social distancing guidelines (20). 
The KAP (Knowledge, Attitude, and Practices) theory states that for the adoption and formation of new behavior, both the acquisition of knowledge and generation of attitude is important (21). In this study, a favorable attitude towards COVID-19 preventive measures was strongly associated with good practice. Likewise, previous studies have reported positive attitude had a significant and robust impact on preventive behavior $(6,19,22,23)$. For instance, participants who felt COVID-19 will be successfully controlled were more likely to refrain from handshaking (13). Similarly, a favorable attitude predicted the intention of handwashing, one of the key precautionary measures against COVID-19 (22). This finding might have implications for the adoption of public health education strategies targeted at improving attitude among a segment of the community with poor practice.

In this study, as compared to being from outside the capital city, being a resident was associated with better practice. The possible explanation for this could be the relatively strict enforcement of COVID-19 Public Health and Social Measures (PHSM) in the city as compared to parts of the country (4). For instance, a mandatory face mask is a requirement to receive any public service in the city. This finding was in agreement with studies that reported implementation of a mask mandate led to widespread uptake of masks $(24,25)$. This result highlights the possible implication of strong regulations on improving compliance with COVID-19 precautionary measures.

This study has several limitations. The study population was clients attending a hospital and might not be representative of the general public, and might have affected variables such as the level of the perceived risk of COVID-19, which might be higher among patients. The study assessed prevention practice based on self-report, which might have inflated the true extent among the respondents. Due to the study design implemented, it is not possible to assess whether risk factors modified practice or changed as a result of practice.

\section{Conclusion}

The level of COVID-19 precautionary practice was unsatisfactory. Having the right attitude towards COVID19 precautionary measures had a strong association with COVID-19 precautionary practice. Stricter public enforcement of COVID-19 preventive measures might have contributed to better adherence to precautionary measures. Public health education strategies targeted at communicating the effectiveness of good practice for the prevention of COVID-19 spread might be beneficial.

\section{Abbreviations}

AOR: Adjusted Odds Ratio; Cl: Confidence Interval; COVID-19: Coronavirus Disease; COR: Crude Odd Ratio; MoH; Ministry of Health; PHSM: Public Health and Social Measures; SPHMMC: Saint Paul's Hospital Millennium Medical College; Severe Acute Respiratory Syndrome Coronavirus 2 (SARS-CoV-2) and WHO: World Health Organization (WHO)

\section{Declarations}




\section{Ethics approval and consent to participate}

Ethical clearance was obtained from the institutional review board of SPHMMC. All respondents underwent informed consent for participation in the study.

\section{Consent for publication}

Not applicable

\section{Availability of data and materials}

The datasets used and/or analyzed during the current study are available from the corresponding author on reasonable request.

\section{Competing Interests}

The authors declare that they have no competing interests

\section{Funding}

Funding was obtained from SPHMMC's research resource mobilization and project management directorate. The study's sponsors had no role in study design, the collection, analysis, interpretation of data, or manuscript preparation.

\section{Authors' Contributions}

HB conceived designed the study, interpreted data, and prepared the manuscript. SM prepared data a collection instrument, analyzed data, and AY analyzed, interpreted data, and reviewed the manuscript. All authors read and approved the final manuscript.

\section{Acknowledgments}

The authors would like to thank data collectors and study participants for gathering and providing information.

\section{References}

1. Huang C, Wang Y, Li X, Ren L, Zhao J, Hu Y, et al. Clinical features of patients infected with 2019 novel coronavirus in Wuhan, China. Lancet. 2020;395(10223):497-506. 
2. Hauser A, Counotte MJ, Margossian CC, Konstantinoudis G, Low N, Althaus CL, et al. Estimation of SARS-CoV-2 mortality during the early stages of an epidemic: A modeling study in Hubei, China, and six regions in Europe. PLoS Med. 2020;17(7):e1003189.

3. The African COVID-19 Critical Care Outcomes Study. Patient care and clinical outcomes for patients with COVID-19 infection admitted to African high-care or intensive care units ( ACCCOS ): a multicentre , prospective, observational cohort study. Lancet. 2021;397(10288):1885-94.

4. Gudina EK, Gobena D, Debela T, Yilma D, Girma T, Mekonnen Z, et al. COVID-19 in Oromia Region of Ethiopia: A review of the first 6 months' surveillance data. BMJ Open. 2021;11(3):1-9.

5. Alene KA, Gelaw YA, Fetene DM, Koye DiN, Melaku YA, Gesesew H, et al. COVID-19 in Ethiopia: A geospatial analysis of vulnerability to infection, case severity and death. BMJ Open. 2021;11:e044606.

6. Ferdous MZ, Islam MS, Sikder MT, Mosaddek ASM, Zegarra-Valdivia JA, Gozal D. Knowledge, attitude, and practice regarding COVID-19 outbreak in Bangladesh: An onlinebased cross-sectional study. PLoS One. 2020;15(10):e0239254.

7. Abdool Karim SS, de Oliveira T. New SARS-CoV-2 Variants - Clinical, Public Health, and Vaccine Implications. N Engl J Med. 2021;384(19):1866-8.

8. Jang GJ, Jang G, Ko S. Factors influencing the preventive practice of international students in south korea against covid-19 during the pandemic. Int J Environ Res Public Health. 2021;18(5):1-9.

9. Luo Y, Yao L, Zhou L, Yuan F, Zhong X. Factors influencing health behaviours during the coronavirus disease 2019 outbreak in China: an extended information-motivation-behaviour skills model. Public Health. 2020;185:298-305.

10. Birhanu Z, Ambelu A, Fufa D, Mecha M, Zeynudin A, Abafita J. Risk perceptions and attitudinal responses to COVID-19 pandemic: an online survey in Ethiopia. BMC Public Health. 2021;21:1-17.

11. Bekele D, Tolossa T, Tsegaye R, Teshome W. The knowledge and practice towards COVID-19 pandemic prevention among residents of Ethiopia. An online cross-sectional study. PLoS One. 2021;16(1):e0234585.

12. Gebreselassie AF, Bekele A, Tatere HY, Wong R. Assessing the knowledge, attitude and perception on workplace readiness regarding COVID-19 among health care providers in Ethiopia - An internet-based survey. PLoS One. 2021;16(3):e0247848.

13. Kebede Y, Yitayih Y, Birhanu Z, Mekonen S, Ambelu A. Knowledge, perceptions and preventive practices towards COVID-19 early in the outbreak among Jimma university medical center visitors, Southwest Ethiopia. PLoS One. 2020;15(5):e0233744.

14. Olum R, Chekwech G, Wekha G, Nassozi DR, Bongomin F. Coronavirus Disease-2019: Knowledge, Attitude, and Practices of Health Care Workers at Makerere University Teaching Hospitals, Uganda. Front Public Heal. 2020;8(181):1-9.

15. World Health Organization. Regional Office for Europe. Survey tool and guidance: rapid, simple, flexible behavioural insights on COVID-19. 2020; Available from: https://apps.who.int/iris/bitstream/handle/10665/333549/WHO-EURO-2020-696-40431-54222eng.pdf?sequence=1\&isAllowed=y. Accessed May 82021. 
16. Duong MC, Nguyen HT, Duong BT. A Cross-Sectional Study of Knowledge, Attitude, and Practice Towards Face Mask Use Amid the COVID-19 Pandemic Amongst University Students in Vietnam. J Community Health. 2021. https://doi.org/10.1007/s10900-021-00981-6

17. Chu DK, AkI EA, Duda S, Solo K, Yaacoub S, Schünemann HJ, et al. Physical distancing, face masks, and eye protection to prevent person-to-person transmission of SARS-CoV-2 and COVID-19: a systematic review and meta-analysis. Lancet. 2020;395(10242):1973-87.

18. Gutu B, Legese G, Fikadu N, Kumela B, Shuma F, Mosisa W, et al. Assessment of preventive behavior and associated factors towards COVID-19 in Qellam Wallaga Zone, Oromia, Ethiopia: A communitybased cross-sectional study. PLoS One. 2021;16(4):e0251062.

19. Azene ZN, Merid MW, Muluneh AG, Geberu DM, Kassa GM, Yenit MK, et al. Adherence towards COVID19 mitigation measures and its associated factors among Gondar City residents: A community-based cross-sectional study in Northwest Ethiopia. PLoS One. 2020;15(12):1-15.

20. Hills S, Eraso Y. Factors associated with non-adherence to social distancing rules during the COVID-19 pandemic: a logistic regression analysis. BMC Public Health. 2021;21(1):1-25.

21. Fan Y, Zhang S, Li Y, Li Y, Zhang T, Liu W, et al. Development and psychometric testing of the Knowledge, Attitudes and Practices (KAP) questionnaire among student Tuberculosis (TB) Patients (STBP-KAPQ) in China. BMC Infect Dis. 2018;18(1):1-10.

22. Chang CT, Lee M, Lee JCY, Lee NCT, Ng TY, Shafie AA, et al. Public KAP towards COVID-19 and Antibiotics Resistance: A Malaysian Survey of Knowledge and Awareness. Int J Environ Res Public Health. 2021;18(8).

23. Lee M, Kang BA, You M. Knowledge, attitudes, and practices (KAP) toward COVID-19: a cross-sectional study in South Korea. BMC Public Health. 2021;21(1):295.

24. Howard J, Huang A, Li Z, Tufekci Z, Zdimal V, van der Westhuizen HM, et al. An evidence review of face masks against COVID-19. Proc Natl Acad Sci U S A. 2021;118(4):1-12.

25. Lyu W, Wehby GL. Community use of face masks and COVID-19: Evidence from a natural experiment of state mandates in the US. Health Aff. 2020;39(8):1419-25.

\section{Supplementary Files}

This is a list of supplementary files associated with this preprint. Click to download.

- Additionalfile1.doc 